\title{
Protective Effect of Ginger Extract against Cisplatin-Induced Nephrotoxicity in Rats
}

\author{
Mohamed H. Sheriff ${ }^{1}$, Al-shimaa M. Abas ${ }^{2}$ and Basem M. Abd- El- Rahman ${ }^{2}$ \\ ${ }^{1}$ Chemistry Department, Faculty of Science, Zagazig University, Egypt \\ ${ }^{2}$ Biochemistry Division, Chemistry Department, Faculty of Science, Zagazig University, Egypt \\ Correspondence: Al-Shimaa M. Abas, E-mail: dr_shmma@yahoo.com, mobile: 01009890366.
}

\section{ARTICLE INFO}

Keywords:

Nephrotoxicity, Ginger extract,

Cisplatin, Caspase-3.

\begin{abstract}
A B S T R A C T
Background: Nephrotoxicity was reported in the initial clinical trials of cisplatin chemotherapy. Aim of study: Our study was designed to evaluate the nephroprotective effect of Ginger extract promoted by cisplatin. Material \& Methods: Animals were divided into7 groups as follow: Group1 (Control): Animals were injected intraperitoneal with $1 \mathrm{ml}$ single saline dose.Group2 (DMSO): Animals were administered orally with1 ml of $6.5 \%$ DMSO for 19 days .Group3 (cisplatin): Animals were injected intraperitoneal with cisplatin $(10 \mathrm{mg} / \mathrm{kg})$ as single dose to induce nephrotoxicity. Group 4 (Ginger only): Animals were administrated orally with $600 \mathrm{mg} / \mathrm{Kg} /$ day of ginger extract for 19 days. Group 5, 6 and7: Animals pretreated with oral dose of ginger extract (200, 400 and $600 \mathrm{mg}$ $/ \mathrm{kg} /$ day respectively) for two weeks before and 5 days after single IP cisplatin $(10 \mathrm{mg} / \mathrm{kg})$. Results: Administration cisplatin caused significant elevation in serum urea, creatinine concentration and kidney tissue levels of MDA and NO. Also caused significant increase in Caspase-3 levels, cisplatin significantly decreased level of $\mathrm{Na}$. it decreased $\mathrm{K}, \mathrm{Mg}$ and $\mathrm{Ca}$ level but statistically non-significant. Also it significantly decreased the antioxidant level of Catalase. Treatment with Ginger extract restored the levels of kidney concentration also oxidative stress markers in groups 5, 6 and 7 and also decrease Caspase-3 level. Also histopathological analysis confirmed that. Conclusion: ginger extract have a protective role in cisplatin induced nephrotoxicity.
\end{abstract}

\section{INTRODUCTION}

Cisplatin

(cisdiamminedichloroplatinum(II),CDDP) is a platinum-based drug ${ }^{[1]}$, compound which has a wide part toward different strong malignancies, for example, head and neck, bladder, lung, ovaries, gonads, and uterus ${ }^{[2]}$. The cytotoxic impact of cisplatin is considered to come about essentially from its cooperation with DNA, by the framing of covalent adducts between certain DNA bases and the platinum compound ${ }^{[3]}$, in spite of its clinical utility, cisplatin treatment has been connected with a few harmful symptoms including ototoxicity, nephrotoxicity, myelosuppression, and peripheral neuropathy ${ }^{[4]}$.

Ginger (Zingiber officinale), an individual from the Zingiberaceae family, is a notable flavor utilized as a part of the everyday consume less calories in numerous Asian nations ${ }^{[5]}$. It was accounted for that ginger likewise had hostile to anti-cancer, anticlotting, anti-inflammatory, and analgesic activities ${ }^{[6]}$. Concentrates of the ginger are wealthy in shagaols and gingerols which show anti-inflammatory, anti-oxidant and anti-carcinogenic 
proprieties under "in vitro" and "in vivo"'systems ${ }^{[7]}$.

\section{Materials and Methods Animal management}

Adult male albino rats, weighing 180 -200 $\mathrm{g}$, were gotten from the Experimental Animal Care Center and were housed in metabolic confines under controlled ecological conditions $\left(25^{\circ} \mathrm{C}\right.$ and a $12 \mathrm{~h}$ light/dark cycle) one week before beginning the trials acclimatization period. The animals were nourished with libtium and given drinking water.

\section{Ginger extract / dose selection:}

Measurements of ginger extract (bought from Sigma- Aldrich Co) was chosen by ${ }^{[8]}$ who expressed that study conducted in male rats at a dosages of 500, 1000 and $2000 \mathrm{mg} / \mathrm{kg}$ body weight for 35 days and results showed that chronic administration of ginger was not related with any death and abnormalities in general conditions, habits, growth, food and water rate consumption. Ginger extract was dissolved initially in DMSO ${ }^{[9]}$ and further diluted in PBS with the final concentration of DMSO $(6.5 \%)$ before administering to the rats. LD50 of cisplatin in rats is $12 \mathrm{mg} / \mathrm{kg}$ body weight ${ }^{[10]}$. The dose of cisplatin was selected on the basis of its ability to induce nephrotoxicity ${ }^{[11]}$.

\section{Experimental design}

To achieve the ultimate goal of this study, following an acclimatization period of one week with standard basal diet, a total of 70 adult male albino rats were divided into seven groups as follow.

Group 1 (Negative control): Animals were intraperitoneally (i.p.) injected with 1 $\mathrm{ml}$ single saline dose and animals were sacrificed after 19 days.

Group 2 (DMSO): Animals were provided orally with $1 \mathrm{ml}$ of $6.5 \%$ DMSO each day for 19 days then scarified.

Group 3 (cisplatin): Animals were injected intraperitoneal (i.p.) with cisplatin $(10 \mathrm{mg} / \mathrm{kg}$ ) (was purchased from Sigma
Chemical Co) as single dose on the 15th day of the experiment and animals were sacrificed after 5 days.

Group 4 (Ginger only): Animals were administrated with oral dose of ginger extract $(600 \mathrm{mg} / \mathrm{kg})$ for 19 days.

Group 5, 6 and 7: Animals pretreated with oral dose of ginger extract (200, 400 and $600 \mathrm{mg} / \mathrm{kg} /$ day respectively) for two weeks before and 5 days after single IP cisplatin $(10 \mathrm{mg} / \mathrm{kg})$. Animals were sacrificed after 19 days.

\section{Collection and sampling of blood}

Toward the finish of experimental period (19 days), animals were fasted for 12 hours. Animals were killed by cervical execution and blood serum was gathered by a described procedure ${ }^{[12]}$. Serum was set up by accumulation of blood in anticoagulant - free tube, at that point left for 10 minutes in water bath at $37^{\circ} \mathrm{C}$ until cluster, at that point centrifuged at $2000 \mathrm{rpm}$ for 10 minutes for separation of serum which was moved into another tube and kept frozen at $-20^{\circ} \mathrm{C}$.

\section{Tissue processing for oxidative parameters and histopathological examination}

After blood collection kidney was evacuated, washed with ice-cold phosphate-buffered saline ( $\mathrm{pH}$ 7.4). The homogenates were centrifuged and the supernatants got were moved into eppendorf tubes, and protected until utilized for lipid peroxidation (MDA), nitric oxide levels, catalase activity and Caspase- 3 concentration. The another piece of kidney was settled in $10 \%$ formalin for histopathological examination .Three $\mu \mathrm{m}$-thick paraffin sections were stained with hematoxylin and eosin $(\mathrm{H}$ and $\mathrm{E})$ for light microscope examination utilizing conventional protocol [13]. Histopathological studies were carried out under a light microscope.

\section{Estimation of biochemical parameters}


Estimation of serum urea and creatinine were performed by colorimetric technique as indicated by ${ }^{[14]},{ }^{[15]}$ respectively. also,Serum potassium,sodium,cacium and magnesium were performed by colorimetric technique as indicated by ${ }^{[16]}$, ${ }^{[17]},{ }^{[18]}$ and ${ }^{[19]}$ respectively.

Level of kidney tissue homogenate MDA, NO and Catalase were determined according to ${ }^{[20]},{ }^{[21]}$ and ${ }^{[22]}$ using colorimetric kit obtained from Biodiagnostic Company (Biodiagnostic, Egypt) Catalogue No. 201-11-0281. 3(Caspase-3/CPP32) ELISA Kit is used to assay the Rat cysteinyl aspartate specific proteinases 3(Caspase-3/CPP32) in the homogenate.

\section{Statistical Analysis}

All results were analyzed by SPSS software (version 14). Data were expressed as mean \pm SD. Comparison of mean values of studied variables among different groups was done using ANOVA test. $\mathrm{P}<0.05$ was considered to be significant ${ }^{[23]}$.

\section{RESULTS}

\section{Kidney function tests in all studied groups.}

Cisplatin caused significant increase in urea and creatinine levels $(\mathrm{P}<0.001)$, $(\mathrm{P}<$ 0.0001) respectively. Administration of ginger extract before and along with cisplatin significantly reduced their levels comparing to cisplatin group (Table 1), (Figures 1-2).

\section{Minerals levels in all studied groups}

Table (2) indicated that serum levels of $\mathrm{Ca}, \mathrm{K}, \mathrm{Mg}$ and $\mathrm{Na}$ showed statistically non-significant difference in DMSO and ginger treated groups compared to control group ( $p>0.05$ ). Also the administration of cisplatin (group 3) showed slight decrease in $\mathrm{Ca}, \mathrm{K}, \mathrm{Mg}$ and $\mathrm{Na}$ levels which statistically non-significant that amounted to $-5.5,-0.8,-1.2$ and $-1.9 \%$ respectively. While in group 5, 6 and 7 serum levels of $\mathrm{Ca}, \mathrm{K}, \mathrm{Mg}$ and $\mathrm{Na}$ were increased compared to cisplatin group. Group 5 (ginger $200+$ cisplatin) showed statistically non-significant increase in serum $\mathrm{Ca}, \mathrm{K}, \mathrm{Mg}$ and $\mathrm{Na}$ of treated rats that amounted to 3.8, 0.1, 0.0 and $1.2 \%$ respectively compared to cisplatin group. Group 6 (ginger 400 + cisplatin) showed statistically non-significant increase in serum $\mathrm{Ca}, \mathrm{K}, \mathrm{Mg}$ and $\mathrm{Na}$ of treated rats that amounted to 4.0, 0.4, 0.8 and $1.5 \%$ respectively compared to cisplatin group. Group 7 (ginger 600 + cisplatin) showed statistically non-significant increase in serum $\mathrm{K}, \mathrm{Mg}$ and $\mathrm{Na}$ of treated rats that amounted to $0.5, \quad 0.9$ and $1.7 \%$ respectively compared to cisplatin group while significantly increased in $\mathrm{Na}$ level which amounted to $5.2 \%$ compared to cisplatin group (Figures 3-6).

\section{Effect of ginger extracts on oxidative stress levels}

The levels of MDA and NO were significantly increased in cisplatin group which amounted to 203.4 and $190.5 \%$ respectively comparing to control group. Administration of ginger extract before and along with cisplatin significantly reduced the levels of No in group 5, 6 and 7 comparing to cisplatin group. Also significantly reduced the levels of MDA in group 7, while showed non-significant decrease in group 5 and 6 comparing to cisplatin group (Table 3), (Figures 7-8).

Effect of ginger extract on antioxidant levels

The level Catalase was significantly decreased in cisplatin group which amounted to $-36.1 \%$ comparing to control group. Administration of ginger extract before and along with cisplatin increased the levels of catalase in group 5, 6 and 7 comparing to cisplatin group (Table 3), (Figures 9).

\section{Effect of ginger extract on caspase - 3 levels.}

The mean level of Caspase-3 showed statistically non-significant increase in DMSO and ginger only treated groups which amounted to 0.8 and $8.5 \%$ respectively compared to control group ( $>0.05)$. 
In group 3 administration of cisplatin induced apoptosis by causing significant elevation in caspase- 3 level in kidney tissue which amounted to $70.3 \%$ compared to control group $(\mathrm{p}<0.001)$.

Treatment with ginger extract reduced the elevation in caspase-3 level in group 5, 6 \&7 which amounted to 29.6, 20.2 and 7.9 $\%$ respectively compared to control group (Table 4), (Figure 10).

\section{Histopathological examination of kidney tissue}

Histological examinations of tissue sections from the kidney showed vacuolated glomeruli and degenerated of some renal tubules with luminal renal cast were observed in the group 3 (cisplatin). While in group 7 (ginger $600+$ cisplatin) the kidney tissues were protected against cisplatin-induced damage and show normal glomeruli and renal tubules with no pathological changes when compared with the control heart tissue slide (Figures 1116).

\section{DISCUSSION}

Cisplatin is an inorganic complex created by a molecule of platinum encompassedby chlorine and ammonia. One of the potential mechanisms by which cisplatin gathers in the cells is by carrier-mediated processes ${ }^{[24]}$. Cisplatin activated once it enters the cell. In the cytoplasm the chloride particles on cisplatin are dislodged by water atoms. This hydrolyzed product is an intense electrophile that can react with any nucleophilic agent, including the sulfhydryl groups on proteins and nitrogen donor atoms on nucleic acids. Cisplatin ties to the N7 reactive focus on purine residues and in that capacity can cause deoxyribonucleic acid (DNA) harm in cancer cells, blocking cell division and so causing apoptotic cell death ${ }^{[25]}$.Despite its efficacy as an antitumor drug, different reactions, including nephrotoxicity ${ }^{[26]}$, hepatotoxicity and cardiotoxicity.

Serum creatinine and urea levels were viewed the principle parameters that decide kidney function ${ }^{[11]}$. In the present study, nephrotoxicity of cisplatin was confirmed by the increased levels of serum urea and creatinine. The rise in the serum levels of these renal biomarkers may be because of the impaired renal functions ${ }^{[27]}$, tubular obstruction, and/or the back-leakage of the renal tubules ${ }^{[11]}$. Such functional disorder in cisplatin exposed rats showed the role of cisplatin to inhibit protein synthesis in the tubular cells ${ }^{[28]}$ or to initiate lipid peroxidation and generation of free radicals in renal tubules ${ }^{[29]}$. The cisplatin toxicity incited serious renal dysfunction that permits the elevated secretion of creatinine from the proximal tubules, a marker of irreversible renal tubular injury ${ }^{[30]}$. Renal function can also be determined by measuring the serum urea level. During the metabolism of protein in the body, the liver produces ammonia which is converted into a byproduct called urea. However, because of renal dysfunction, urea is released into the bloodstream as serum urea. Therefore, increased level of serum urea is directly relative to increasing the percentage of renal damage ${ }^{[30]}$. Similar findings were already detailed in various studies ${ }^{[31]}$. The kidney biomarkers increased due to the direct dangerous effect of cisplatin on the glomerular and tubular structures through the generation of ROS. Constriction of the mesangial cells with subsequent alteration in the filtration surface area came about because of the generation of ROS ${ }^{[32]}$.

Our results are in line with $\mathrm{Xu}$ et al. ${ }^{[33]}$ who detailed that cisplatin is also harmful to renal vasculature which results in diminished blood flow leading to ischemic injury of the kidneys, showing up as a decrease in the glomerular filtration rate which is reflected as increased serum creatinine and BUN levels.

Our results are in accordance with Hongzhou et al. ${ }^{[34]}$ who revealed that cisplatin-induced nephrotoxicity was apparent by increase in serum creatinine and urea levels in the rats.

Treatment with ginger extract significantly reduced the elevation in blood urea and creatinine levels in treated groups. Our 
results are in agreement with Khan et al. ${ }^{[35]}$ indicated that ginger extract markedly diminished the blood urea nitrogen concentrations in experimental mice in a non-linear fashion concerning the administered dose. Nonetheless, little changes observed in the levels of creatinine in these animals as compared with the control group.

Minerals are inorganic substances, present in all body tissues and fluids and their presence is vital for the support of certain physicochemical processes which are basic to life. Serious disruptions in physiologic functions can be resulted from imbalance of any of the minerals ${ }^{[36]}$.

Renal magnesium wasting, and electrolyte disturbances like hypomagnesia, hypocalcaemia, Hyponatremia and hypokalemia are common with cisplatin treatment.so routine monitoring of magnesium in plasma is recommended to stay away from tetany ${ }^{[37]}$.

Hypomagnesaemia is a common side-effect in patients treated with cisplatin; the possible mechanisms of cisplatin induced hypomagnesaemia might be the direct injury to magnesium reabsorption in the ascending limb of loop of henle, also the distal tubule ${ }^{[38]}$.

Hypocalcaemia is another known side effect related with cisplatin chemotherapy. Excessive urinary loss of calcium, diminished renal uptake of calcium because of the proximal tubular damage, because of low tissue response of parathyroid hormone and low serum magnesium levels, is the possible mechanism behind cisplatin induced hypocalcaemia ${ }^{[39]}$.

Hypokalemia is another common electrolyte abnormality happened during cisplatin treatment; it is due to increased renal reabsorption capacity observed due to decreased intestinal absorption of potassium. Further magnesium and potassium metabolism subjected to predicable changes in intestinal absorption and renal excretion with each cisplatin treatment ${ }^{[40]}$.
Hyponatremia is not an uncommon clinical disorder, in another studies researchers have found that both renal salt wasting syndrome and syndrome of inappropriate antidiuretic hormone secretion have been reported as the underlying mechanism for cisplatin chemotherapy induced hyponatremia ${ }^{[41]}$.

Our results are in line with (Arany and Safirstein, ${ }^{[42]}$ who reported that Clinically, cisplatin nephrotoxicity is frequently observed after 10 days of cisplatin administration and is manifested as lower glomerular filtration rate and decreased serum magnesium and potassium levels.

Results are in agreement with (Nikhil and Aravindh, [43] that Profound that hypomagnesaemia, hypokalemia and hypocalcaemia have been reported in patients on cisplatin therapy. Also are in agreement with (Bryan et al., 2017) ${ }^{[44]}$ who detailed that Platinum chemotherapy, especially cisplatin, is usually related with electrolyte imbalances, including hypomagnesemia, hypokalemia, hypophosphatemia, hypocalcemia and hyponatremia.

Administration of ginger extract restored the levels of $\mathrm{Ca}, \mathrm{K}, \mathrm{Mg}$ and $\mathrm{Na}$ to normal value and this are in agreement with Whang et al. [45] who revealed that cisplatin-induced cause excessive urinary loss of magnesium and potassium ${ }^{[46]}$ could be partly restored by supplementation.

Our results are in accordance with Joshua et al. ${ }^{[47]}$ who reported that there was a significant decrease in serum sodium and calcium concentrations in ginger extracttreated groups when compared to the control group.

The oxidative stress has emerged as the principle mechanism in cisplatin-induced nephrotoxicity ${ }^{[2]}$. It has been reported that excess reactive oxygen species (ROS) production as well as antioxidant system depletions are consequent to cisplatin administration ${ }^{[48]}$. The likely sources of ROS during cisplatin administration include the mitochondrial electron transport chain system ${ }^{[49]}$, xanthine oxidase ${ }^{[50]}$, 
cytochrome P450 enzymes [51], and NADPH oxidase ${ }^{[52]}$. Since, ROS are highly reactive and unstable; they may attack and modify cellular components such as lipids, proteins, and DNA, resulting in cellular stress ${ }^{[53]}$. ROS accumulation also activates important signaling pathways, including apoptotic pathway, which leads to cell death in the event of cisplatin-induced nephrotoxicity ${ }^{[54]}$.

Our results demonstrated that cisplatin treatment caused significant increase in kidney MDA, NO levels and significant decrease in catalase activity (Table 3 ). Results reported by Liwei et al. ${ }^{[55]}$ showed that cisplatin induces an increase in oxidative stress and alters intracellular $\mathrm{Ca}^{2}$ concentration, including cytosolic and mitochondrial $\mathrm{Ca}^{2}$ in cisplatin-sensitive SKOV3 cells. Cisplatin induces mitochondrial harm and triggers the mitochondrial apoptotic pathway in cisplatin-sensitive SKOV3 cells.

Soliman et al. ${ }^{[56]}$ declared that Cisplatin induced a significant increase in malondialdehyde, and nitric oxide levels. However, glutathione, superoxide dismutase, and catalase levels were significantly decreased.

The proposed mechanism of induced nephrotoxicity of cisplatin could be clarified as in the accompanying: During the physiological process, the mitochondrial respiratory chain continuously generates ROS. Around 2\% of the electrons which influx along the respiratory chain escape from the chain and partially reduces molecular oxygen, originating superoxide anion $(\mathrm{O} 2-\bullet)$. Superoxide anion, the precursor of most of the reactive oxygen species generated in mitochondria as for example hydroxyl radicals HO. An effective mitochondrial antioxidant defense system maintains the balance between ROS generation and detoxification $^{[57]}$. Cisplatin is un able to make balance between the oxidantantioxidant ratio by (i) increasing ROS generation, principally hydroxyl radical and (ii) decrease of the antioxidant defense system which are SOD, CAT and GSH. These radicals can elicit extensive tissue damage, reacting with membrane lipids, proteins and nucleic acids ${ }^{[58]}$. Our results agreed with Chirino et al. ${ }^{[59]}$ reported that the renal content of peroxynitrite and nitric oxide is increased in cisplatin treated rats; furthermore, cisplatin caused significant increases in the level of MDA, and impaired the activitiy of CAT.

Also our results are in accordance with Janakiraman, ${ }^{[60]}$ reported an increase in lipid peroxidation and decrease in the activities of antioxidant enzymes upon similar cisplatin treatment of rats.

Antioxidants have proven to be effective in ameliorating cisplatin-induced toxicity. Ginger extract is a potent antioxidant which is reported to have antitumor effect and to enhance the effect of many known anticancer agents in addition to reducing their toxicities as well. This is in agreement with Kwanjit et al. ${ }^{[61]}$ who reported that administration of ginger extract cause increased level of catalase while decreased levels MDA and NO.

Our results are in line with Nasri et al. ${ }^{[13]}$ who showed that, high levels of polyphenolic and flavonoid compounds with high antioxidant activity for ginger. The presence of polyphenols and flavonoids in the Z $\mathrm{Z}$. officinale extract might be responsible for the antioxidant and nephroprotective activities.

Mitochondria play a vital role in the signal transduction of apoptosis. The intrinsic pathway included disturbance of mitochondrial membrane potential results in the modulation of Bcl-2 family of proand anti-apoptotic proteins and release of cytochrome $\mathrm{c}$ and/or apoptosis inducing factor (AIF) from the mitochondria into the cytosol. When cytochrome $\mathrm{c}$ is released into the cytosol, it forms an apoptosome with Apaf-1 and procaspase-9. This causes the activation of caspase-9, which additionally activates caspase-3, leading to apoptosis ${ }^{[62]}$.

The activation of caspase is considered to have a pivotal role in the initiation and 
execution of apoptosis induced by various mechanisms stimuli. When cells are undergoing apoptosis, executioner caspase3 triggers cellular proteins and DNA fragmentation factor that cause characteristic changes of apoptosis ${ }^{[63]}$.

In this study administration of cisplatin induced apoptosis by causing significant elevation in caspase-3 level in heart tissue which amounted to $70.3 \%$ compared to control group (Table 4)

Saad et al. ${ }^{[29]}$ are in line with our results who reported that the activation of mitochondrial pathways was important in apoptosis induced by cisplatin, which leads to the release of cytochrome $\mathrm{c}$, activation of caspase 3 and entry into the execution phase of apoptosis.

The ability of ginger to down regulate caspase-3 activity may be attributed to its antiglycation and antioxidant properties. This was in agreement with Saraswat et al. [64] who noticed the antiglycating effect of ginger in the lens of diabetic rats.

In this study histological examination of tissue showed vacuolated glomeruli and degenerated of some renal tubules with luminal renal cast were observed in the cisplatin group.

In this study, cisplatin was found to induce many histopathological alterations in the kidney as necrosis of the renal tubular cells together with karyolytic and pyknotic nuclei, degeneration of the glomeruli and widening of the urinary space. These histopathological changes are in line with findings of many other investigators ${ }^{[65]}$. Our results are in accordance with Kumar et al. [66] who detailed that cisplatininduced nephrotoxicity was assessed by change in levels of blood urea, creatinine, and histopathology of the kidney.

While in group 7 (ginger $600+$ cisplatin) the kidney tissues were protected against cisplatin-induced damage and showed normal glomeruli and renal tubules with no pathological changes when compared with the control heart tissue slide (Figure 11:16). This is in agreement with who reported that there is no histological difference between control and ginger extract groups, ginger is safe and well tolerated and coadministration of ginger extract in dose of $250 \mathrm{mg} / \mathrm{kg}$ with diclofenac sodium partially ameliorated the histological changes produced in the liver by diclofenac toxicity El-Kordy and Makhlouf, ${ }^{[67]}$.

Ginger is treating kidney protector of inflammation resulting from cisplatin drug, where the histopathology results supported these findings. The results agreed with Osama et al. ${ }^{[68]}$ who announced that treatment with different extracts of ginger ameliorated kidney tissues.

\section{REFERENCES}

1-Ali, B.H. and Al Moundhri, M.S. (2006): Agents ameliorating or augmenting the nephrotoxicity of cisplatin and other platinum compounds: a review of some recent research. Food Chem. Toxicol.,(44): 1173-1183.

2- Oh,G.S.; Kim,H.J.; Shen,A.; Lee,S.B; Yang,S.H. and Shim,H.(2016).New therapeutic concept of NAD redox balance for cisplatin nephrotoxicity. Biomed. Res.Int.4048390.

3-Yousef, M.I., Saad, A.A. and ElShennawy, L.K. (2009): Protective effect of grape seed proanthocyanidin extract against oxidative stress induced by cisplatin in rats. Food Chem. Toxicol., (47): 11761183.

4-Oh, G.S.; Kim,H.J. ; Shen,A.; Lee,S.B.; Khadka,D. and Pandit,A.(2014).Cisplatin-induced kidney dysfunction and perspectives on improving treatment strategies. ElectrolyteBloodPress. $12,55-65$.

5-Demin, G. and Yingying, Z. (2010) Comparative antibacterial activities of crude polysaccharides and flavonoids from Zingiber officinale and their extraction. American Journal of Tropical Medicine 5: 235-238. 
6-Yiming, L., Van, H. T., Colin, C. D., and Basil, D. R. (2012). Preventive and Protective Properties of Zingiber officinale (Ginger) in Diabetes Mellitus, Diabetic Complications, and Associated Lipid and Other Metabolic Disorders: A Brief Review. Evidence-Based Complementary and Alternative Medicine, 2012(516870): $1-10$.

7-Surh, Y.J. (2002) Food Chem Toxicol. 40, 1091-1097.

8-Rong, X.; Peng, G.; Suzuki, T.; Yang, Q.; Yamahara, J. and Li, Y. (2009) A 35day gavage safety assessment of ginger in rats. Regul Toxicol Pharmacol ; 54: 118-23.

9-Bardi, D.A.; Halabi, M.F.; Abdullah, N.A.; Rouhollahi, E.; Hajrezaie, M.; Abdulla, M.A.(2013). BioMed Research Int. 1-10.

\section{0-Platinum}

IPoCS(IPCS):

Environmental Health Criteria 125. Geneva: World Health Organisation; (1991).

11-Azu, O.O.; Francis, I.O.D.; Abraham, A.O.; Crescie, C.N.; Stephen, O.E. and Abayomi, 0.0. (2010): Protective Agent, Kigelia Africana Fruit Extract, Against Cisplatin-Induced Kidney Oxidant Injury in Sprague-Dawley Rats. Asian J Pharma Clin Res. 3: 84-88.

12-Thavasu, P.W.; Longhurst, S.; Joel, S.P.; Slevin, M.L.and Balkwill, F.R. (1992). Measuring cytokine levels in blood. Importance of anticoagulants, processing and storage conditions. J Immunol Methods 153: $115-124$.

13-Nasri, H.;Mortazavi, M.; Ghorbani, A.; Shahbazian, H.; Kheiri, S. and Baradaran, A. (2012) Oxford-MEST classification in IgA nephropathy patients: A report from Iran. J Nephropathology $1: 31-42$.
14-Kaplan, A. Urea and kaplan (1984) Clin Chem The C.V. and Mosby Co. St Louis. Toronto. Princeton;1257-1260 and 437 and 418.

15-Murray, R.L. Creatinine and kaplan (1984) Clin Chem The C.V. and Mosby Co. St Louis. Toronto. Princeton, 1261-1266 and 418 .

16-Hillman,G.; Beyer,G. and Klin,Z. (1967) , Biochem.5,93.

17-Henry,R.F.(1974) clinical chemistry principles and technics. $2^{\text {nd }} E d$, Harper and Row, Harper and Row, Hargersein , M.D.

18-Connerty , H.V.(1996) Am J Clin Path Vol 45,No 3; 200-296.

19-Thomas,L.(1998) Clinical Laboratory Diagnostic $1^{\text {st }}$ ed Frankfurt;Th-Books Verlagsgesellscaft;p. 231-41.

20-Ohkawa,H.;Ohishi,W.and Yagi,K. (1979) Anal.Biochemical,95,351.

21-Montgomery and Dymock,J.F( 1961)Analyst, $86,414-416$.

22-Aebi, H.(1984)Methodes Enzymol 105,121-126.

23-Levesque, $\quad$ R.(2007) SPSS Programming and Data Management: Guide for SPSS and SAS Users, 4th ed., SPSS Inc., Chicago. IL 60606-6412.

24-Dresser, M.J.; Leabman, M.K.; Giacomini ,K.M.(2001) Transporters involved in the elimination of drugs in the kidney: Organic anion transporters and organic cation transporters. J Pharm Sci 2001;90: 397-421.

25-Beck, D.J.; Brubaker, R.R(1973). Effect of cisplatinum(II)diamminodichloride on wild type and deoxyribonucleic acid repair deficient mutants of Escherichia coli. 
J.Bacteriol. 116:1247-1252. [PubMed: 4584807]

26-De Jongh, F.E., van Veen, R.N., Veltman, S.J., de Wit, R., van der Burg, M.E. and van den Bent, M.J. (2003):Weekly high-dose cisplatin is a feasible treatment option: analysis on prognostic factors for toxicity in 400 patients. British J Cancer.,(88):1199-206.

27-Anusuya, N.; P. Durgadevi,; A. Dhinek and S. Mythily, (2013). Nephroprotective effect of ethanolic extract of garlic (Allium sativum L.) on cisplatin induced nephrotoxicity in male wistar rats. Asian J Pharm Clin Res. 6(Suppl 4):97-100

28-Adejuwon, A.S.; Femi-Akinlosotu, O.; Omirinde, J.O.; Owolabi, O.R. and Afodun, A.M.(2014): Launaea taraxacifolia ameliorates cisplatin- induced hepato-renal injury. Eur J Medicinal Plants. 4 (5): 528-541. 10.9734/EJMP/7314.

29-Saad, A.A.; Youssef, M.I. and ElShennawy, L.K.(2009): Cisplatin induced damage in kidney genomic DNA and nephrotoxicity in male rats: the protective effect of grape seed proanthocyanidin extract. Food Chem Toxicol. 47 (7): 14991506. 10.1016/j.fct.03.043.

30-Dickey, D.T.; Muldoon, L.L.; Doolittle, N.D.; Peterson, D.R. ; Kraemer D.F. and Neuwelt, E.A.(2008).Effect of $\mathrm{N}$-acetylcysteine route of administration on chemoprotection against cisplatininducedtoxicity in rat models. Cancer Chemotherapy Pharmacol., 62: 235-241.

31-Arhoghro, E.M.; Kpomah, D.E. and Uwakwe, A.A.(2012):Ocimum gratissimum aqueous extract enhances recovery in cisplatin - induced nephrotoxicity in albino wistar rats. Indian J Drugs \& Diseases. 2012, 1 (5): 129-142.

32-Aydogan, S.; Yapislar, H.; Artis, S. and Aydogan, B.(2008): Impaired erythrocytes deformability in $\mathrm{H} 2 \mathrm{O} 2$ - induced oxidative stress: Protective effect of L carnosine. Clin Hemorheol Microcirc. 39: 93-98.

33-Xu, Y.; Ma,H.; Shao,J.; Wu,J.; Zhou,L. and Zhang,Z. (2015). Arolefortubular necroptosisincisplatininducedAKI. J. Am.Soc.Nephrol. 26, $2647-$ 2658.

34-Hongzhou, Meng.; Guanghou, Fu.; Jie, Shen.; Kezhen, Shen.; Zhijie, Xu.; Yiming, Wang.; Baiye, Jin. and Hao, Pan.(2017) Ameliorative Effect of Daidzein on Cisplatin-Induced Nephrotoxicity in Mice via Modulation of Inflammation, Oxidative Stress, and Cell Death. Oxidative Medicine and Cellular Longevity Volume 2017, Article ID 3140680 .

35-Khan, R.A.; Khan, M.R. ; Sahreen, S.and Bokhari, J.(2010). Prevention of CCl4-induced nephrotoxicity with sonchus asper in rat. Food and Chemical Toxicology. ;48(8-9):2469-2476.

36-Thomas, H. (2011). Management of Hypertension. American Journal of Hypertension. 24: 898-903.

37-Shafaq, N. and Tabassum, M.(2011) Effectiveness of carnosine on disturbed electrolytes homeostasis induced by cisplatin. Afr J Biotechnol. 10(37):72867293.

38-Kazem, A.; Mehdi, S.T. and Marjaneh, M.(2010). Evaluation of intravenous magnesium supplementation as prophylaxis for cisplatin-induced hypomagnesemia. Middle East J Cancer. 1(3):109-114.

39-Rebholz, C.M., Gu., D., Chen, J., Huang, J.F., Cao, J., Chen J.C., He, J., ... (2012). Physical activity reduces salt sensitivity of blood pressure: the Genetic Epidemiology Network of Salt Sensitivity 
Study. American Journal of Epidemiology. 176(7): 106-113.

40-Xin, Y.; Kessarin, P.; Neil, K. and Kenneth, N.(2007). Cisplatin nephrotoxicity: A review. Am J Med Sci. 334(2):116-124.

41-Tamim, H.; Shadi, L.; Bassel, J.; Fayez, K.; Mohamad, N.A. and Ashok, P.(2010). Cisplatin-induced renal salt wasting syndrome. South Med J. 103(8):793-799.

42-Arany, I. and Safirstein, R.L.(2003) Cisplatin nephrotoxicity. Semin Nephrol 23: 460-464.

43-Nikhil,s. and Aravindh, S.A.(2016) Electrolyte Abnormalities in Cisplatin Based Chemotherapy. Indian J Physiol Pharmacol; 60(3): 298-299.

44-Bryan, Oronsky.; Scott, Caroen. ;Arnold, Oronsky.;Vaughn, E. Dobalian.;Neil, Oronsky.;Michelle, Lybeck.;Tony, R. Reid. and Corey, A. Carte.(2017). Electrolyte disorders with platinum-based chemotherapy: mechanisms, manifestations and management. Cancer Chemother Pharmacol -017-3392-8.

45-Whang, R.; Whang, D.D.; Ryan, M.P.(1992): Refractory potassium repletion. A consequence of magnesium deficiency. Arch Intern Med ;152:40-45.

46-Buckley, J.E.; Clark, V.L. Meyer, T.J.; Pearlman, N.W.(1984): Hypomagnesemia after cisplatin combination chemotherapy. Arch Intern Med ;144:2347-2348.

47-Joshua, Adamu. Tende.; Joseph, Olusegun. Ayo.; Aliyu, Mohammed. and Abdulkadir, Umar. Zezi.(2014) Effect of Garlic (Allium Sativum) and Ginger (Zingiber Officinale) Extracts on HaematoBiochemical Parameters and Liver Enzyme Activities in Wistar Rats. International
Journal of Nutrition and Food Sciences. Vol. 3, No. 5 pp. 380-386.

48-Domitrovi'c,R.; $\quad$ Cvijanovi'́c,O.; Pernjak-Pugel,E.; Skoda,M.; Mikeli'c,L. and Crn`cevi'c-Orli'c,Z. (2013). Berberineexertsnephroprotectiveeffectagain stcisplatin- induced kidney damage through inhibition ofoxidative/nitrosativestress, inflammation, autophagyandapoptosis. Food Chem.Toxicol. 62, 397-406.

49-Pan,H.; Chen,J.; Shen,K.; Wang,X.; Wang,P., AndFu,G.(2015).Mitochondrial modulation byEpigallocatechin3Gallateamelioratescisplatininducedrenal injury through decreasing oxidative/nitrativestress, inflammationandNF-kB in mice. PLoS ONE 10:e0124775.

50-Yousef,M.I. and Hussien,H.M. (2015) .Cisplatin-inducedrenaltoxicityviatumor necrosisfactorainterleukin6,tumorsuppressorP53,DNAda mage,xanthine oxidase ,histological changes, oxidativestressandnitricoxideinrats :protective effect of ginseng. Food Chem.Toxicol. 78, 17-25.

51-Pabla, N.and Dong, Z.(2008) Cisplatin nephrotoxicity: mechanisms and renoprotective strategies. Kidney Int. 73:994-1007.

52-Wang,Y.; Luo,X.; Pan,H.; Huang,W.; Wang,X. and Wen,H. (2015) . Pharmacologicalinhibition of NADPH oxidase protects against cisplatin induced nephrotoxicity in mice by two step mechanism. Food Chem.Toxicol. 83, 251260.

53-Jaiman,S.; Sharma,A.K.; Singh,K. and Khanna,D. (2013) .Signalling mechanisms involved in renalpathologicalchangesduringcisplatininduced nephropathy. Eur. J.Clin.Pharmacol. 69, 1863-1874. 
54-Song,K.I.; Park,J.Y. ;Lee,S. ;Lee,D. ;Jang,H.J. and Kim,S.N.(2015). Protective effect of tetrahydro curcumin against cisplatin-inducedrenaldamage: in vitroandinvivostudies. PlantaMed. 81, 286291.

55-Liwei, M.A.; Wang,H.; Wang,C.; Su,J; Xie,Q; Xu,L; Yu,Y.; Liu,S.; Li,S.; Xu,Y. and Li,Z.(2016) Aging Dis. 7(3), 254-266.

56-Soliman,A.M.;

Marzouk,M. and

Nutrients 8, 264, 1-9.

57-Santos,N.A.;

Bezerra,C.S.;

Martins,N.M.; Curti,C.; Bianchi,M.L. and Santos,A.C.(2008). Cancer Hemother Pharmacol, 61(1), 145-155.

58-Santos,N.A.;

Bezerra,C.S.;

Martins,N.M.; Curti,C.; Bianchi,M.L. and Santos,A.C.(2007). Arch Toxicol, 81(7), 495-504.

59-Chirino, Y.I.; Hernandez-Pando, R. and Pedraza-Chaverri, J.(2004) Peroxynitrite decomposition catalyst ameliorates renal damage and protein nitration in cisplatin-induced nephrotoxicity in rats. BMC Pharmacol ;4:20.

60-Janakiraman, M.(2015) Antioxidant and protective effects of Vitex negundo against Cisplatin induced nephrotoxicity in male albino rats. International Journal of Pharmaceutical \& Biological Archive. 5(5):95-102.

61-Kwanjit, D.; Jitprapa, K.; Bung-orn, S. and Suphat, S.(2017) Antioxidant activity of ginger extract as a daily supplement in cancer patients receiving adjuvant chemotherapy. Cancer Management and Research, 9 11-18

62-Zhang, R.; Humphreys, I.; Sahu, R.P.; Shi, Y. and Srivastava, S.K.(2008). In vitro and in vivo induction of apoptosis by capsaicin in pancreatic cancer cells is mediated through ROS generation and mitochondrial death pathway. Apoptosis. 13:1465-1478.

63-Tong, X.; Lin, S.; Fujii, M. and Hou, D-X. (2004). Molecular mechanisms of echinocystic acid-induced apoptosis in HepG2 cells.Biochem.Biophys. Res.Comm., 321: 539-546.

64-Saraswat, M.; Suryanarayana, P.; Reddy, P.Y.; Patil, M.A.; Balakrishna, N.and Reddy, G.B., (2010). Antiglycating potential of Zingiber officinalis and delay of diabetic cataract in rats. Mol Vis. 16, $1525-1537$.

65-Fouad, A.A.; Morsy, M.A. and Gomaa ,W. (2008) Protective effect of carnosine against cisplatin-induced nephrotoxicity in mice. Environmental Toxicology and Pharmacology 25: 292 297.

66-Kumar, P.; Barua, C.C.; Sulakhiya, K. and Sharma, R.K. (2017) Curcumin Ameliorates Cisplatin-Induced Nephrotoxicity and Potentiates Its Anticancer Activity in SD Rats: Potential Role of Curcumin in Breast Cancer Chemotherapy. Front. Pharmacol. 8:132.

67-El-Kordy,E.A. and Makhlouf,M.M. (2014). Life Sci J, 11(8), 248-258.

68-Osama, M.B.; Saber, A.S. and Hala, M. A. (2016). Ameliorative effect of ginger extract against pathological alterations induced in mice bearing solid tumors. Journal of Bioscience and Applied Research, Vol.2 No.3, PP.185-196. 


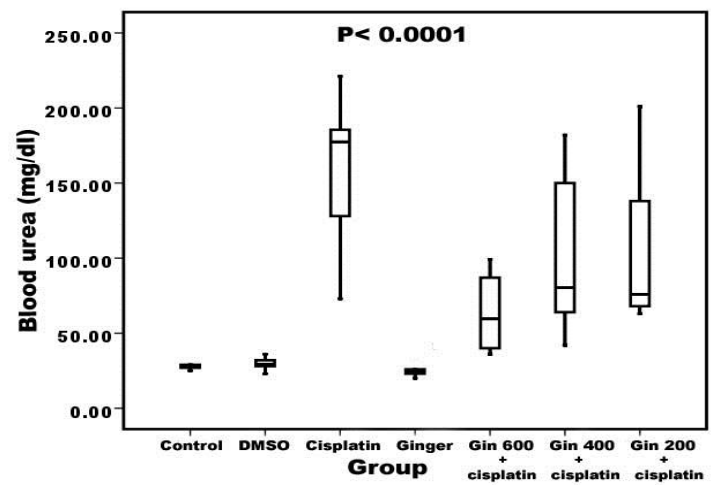

Figure 1: Box plots of blood urea for comparison between laboratory data of all groups in kidney disease. The box represents the interquartile range. The whiskers indicate the highest and lowest values, and the line across the box indicates the median value. Overall significance of differences between laboratory data of all groups was determined by ANOVA test $(\mathrm{p}<0.0001)$

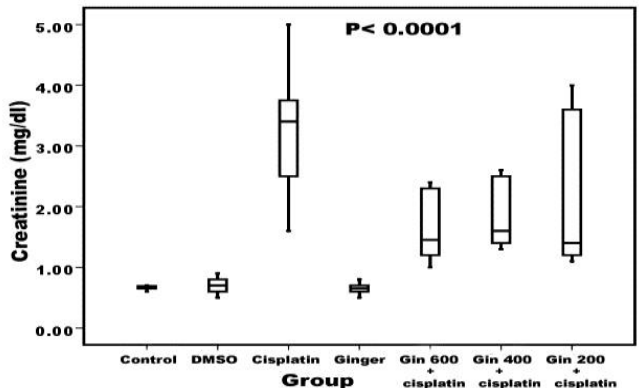

Figure 2: Box plots of creatinine for comparison between laboratory data of all groups in kidney disease. The box represents the interquartile range. The whiskers indicate the highest and lowest values, and the line across the box indicates the median value. Overall significance of differences between laboratory data of all groups was determined by ANOVA test.

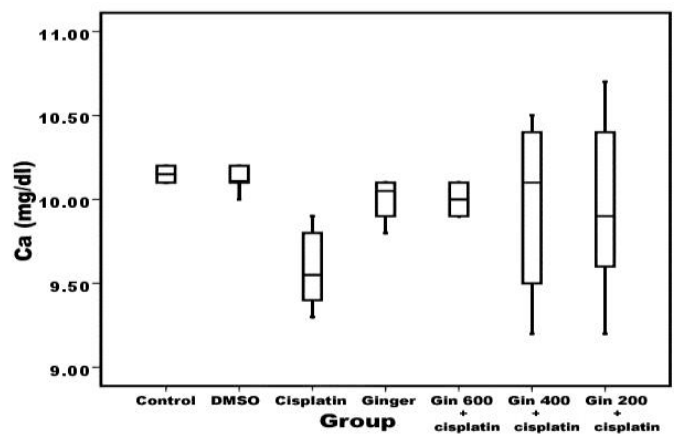

Figure 3: Box plots of $\mathrm{Ca}$ for comparison between laboratory data of all groups in kidney disease. The box represents the interquartile range. The whiskers indicate the highest and lowest values, and the line across the box indicates the median value. Overall significance of differences between laboratory data of all groups was determined by ANOVA test.

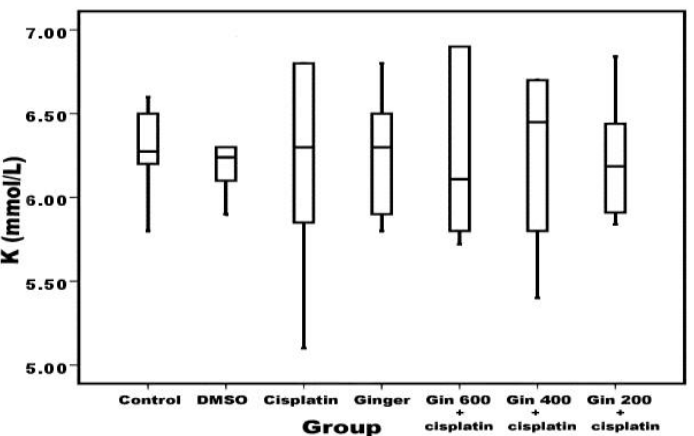

Figure 4: Box plots of $\mathrm{K}$ for comparison between laboratory data of all groups in kidney disease. The box represents the interquartile range. The whiskers indicate the highest and lowest values, and the line across the box indicates the median value. Overall significance of differences between laboratory data of all groups was determined by ANOVA test.

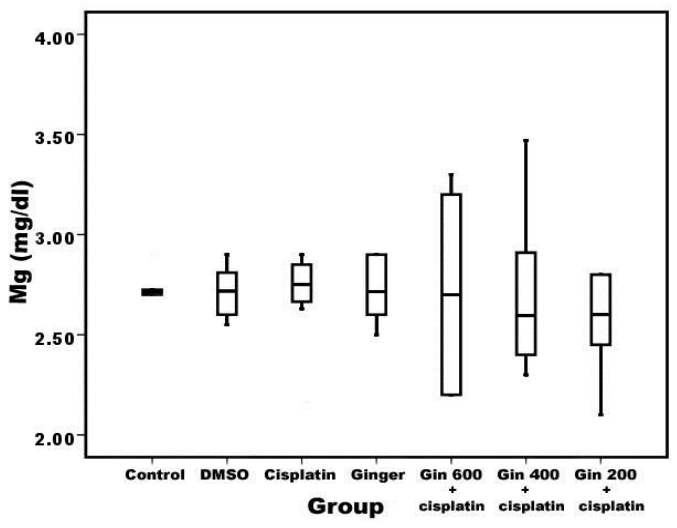

Figure 5: Box plots of $\mathrm{Mg}$ for comparison between laboratory data of all groups in kidney disease. The box represents the interquartile range. The whiskers indicate the highest and lowest values, and the line across the box indicates the median value. Overall significance of differences between laboratory data of all groups was determined by ANOVA test.

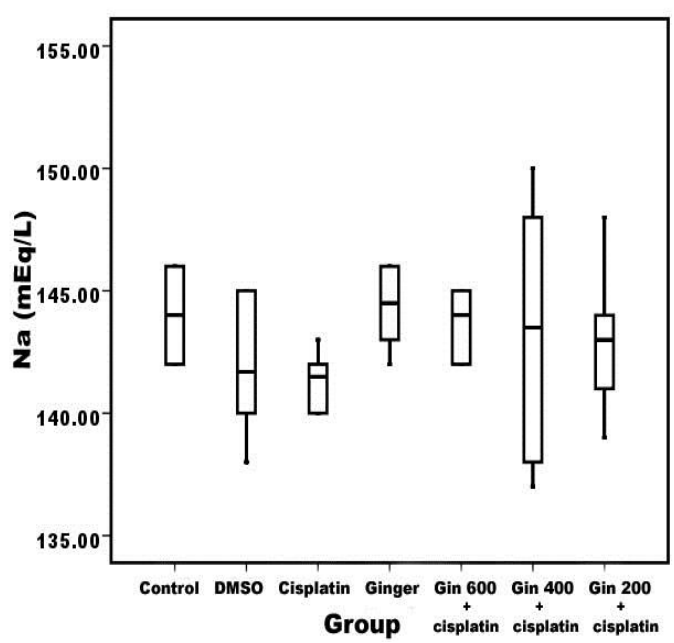


Figure 6: Box plots of $\mathrm{Na}$ for comparison between laboratory data of all groups in kidney disease. The box represents the interquartile range. The whiskers indicate the highest and lowest values, and the line across the box indicates the median value. Overall significance of differences between laboratory data of all groups was determined by ANOVA test.

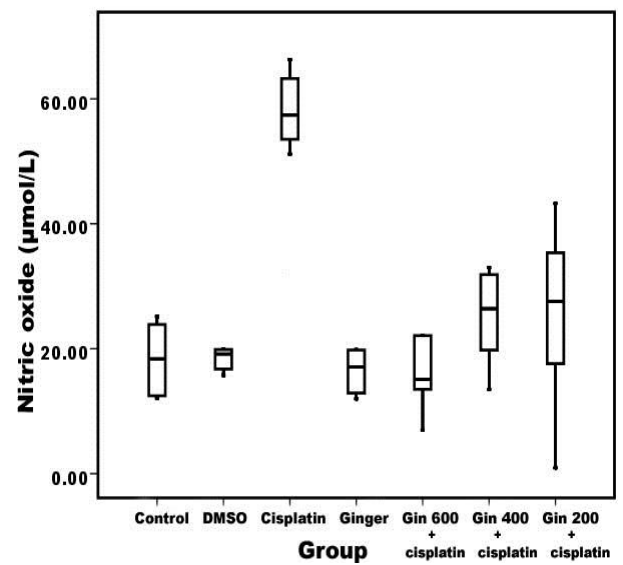

Figure 7: Box plots of nitric oxide for comparison between laboratory data of all groups in kidney disease. The box represents the interquartile range. The whiskers indicate the highest and lowest values, and the line across the box indicates the median value. Overall significance of differences between laboratory data of all groups was determined by ANOVA test.

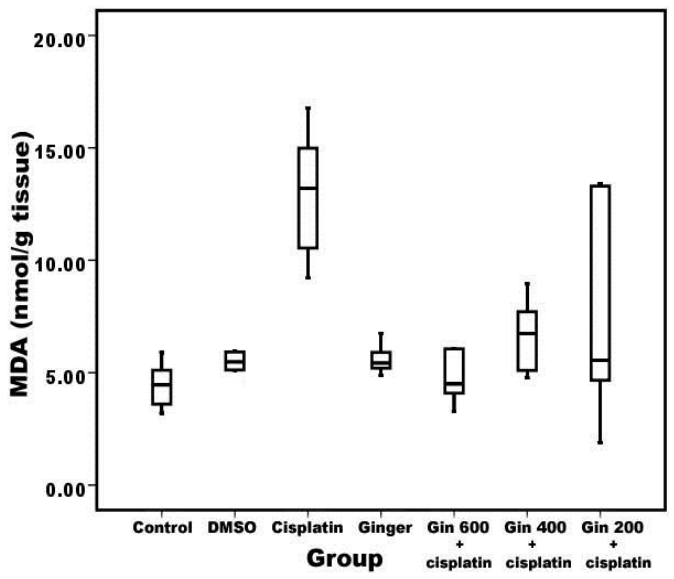

Figure 8: Box plots of MDA for comparison between laboratory data of all groups in kidney disease. The box represents the interquartile range. The whiskers indicate the highest and lowest values, and the line across the box indicates the median value. Overall significance of differences between laboratory data of all groups was determined by ANOVA test.

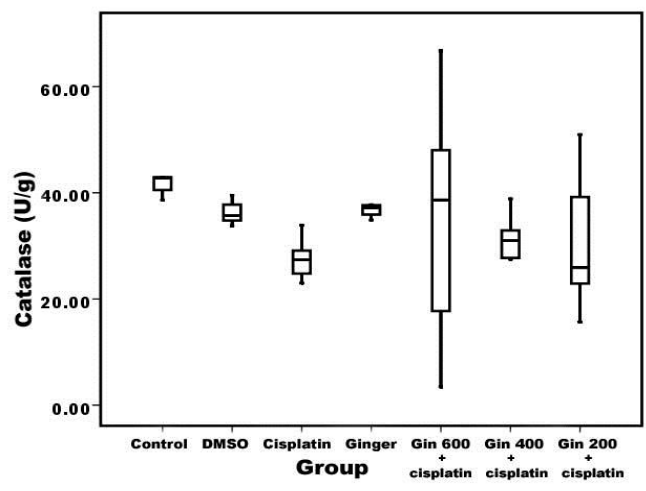

Figure 9: Box plots of catalase for comparison between laboratory data of all groups in kidney disease. The box represents the interquartile range. The whiskers indicate the highest and lowest values, and the line across the box indicates the median value. Overall significance of differences between laboratory data of all groups was determined by ANOVA test.

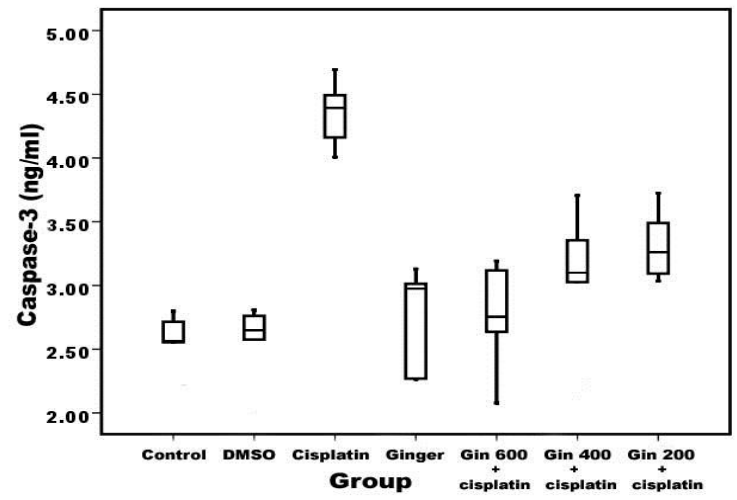

Figure 10: Box plots of caspase-3 for comparison between laboratory data of all groups in kidney disease. The box represents the interquartile range. The whiskers indicate the highest and lowest values, and the line across the box indicates the median value. Overall significance of differences between laboratory data of all groups was determined by ANOVA test. 


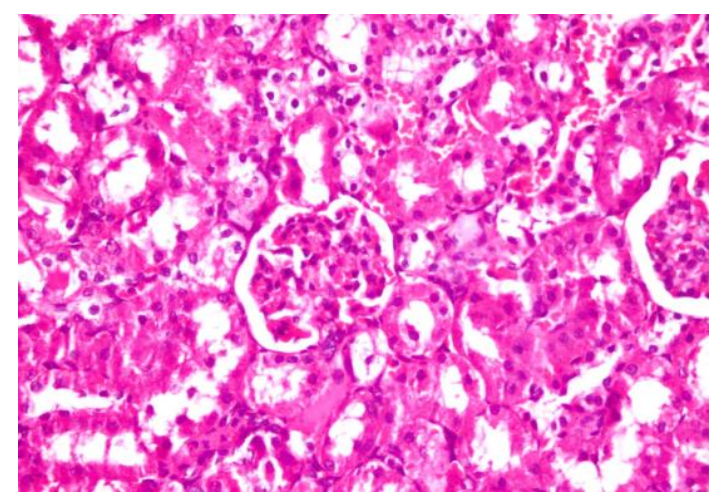

Figure 11: Control group: kidneys showing normal glomeruli and renal tubules

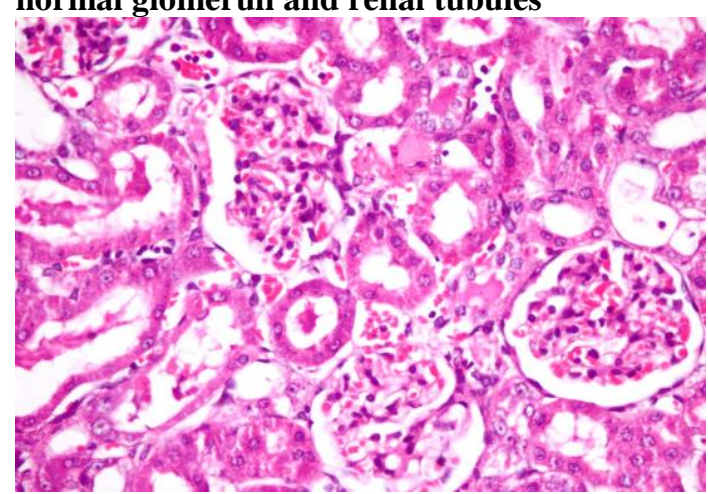

Figure 12: cisplatin (positive) group: kidneys showing vacuolated glomeruli and degenerated of some renal tubules with luminal renal cast

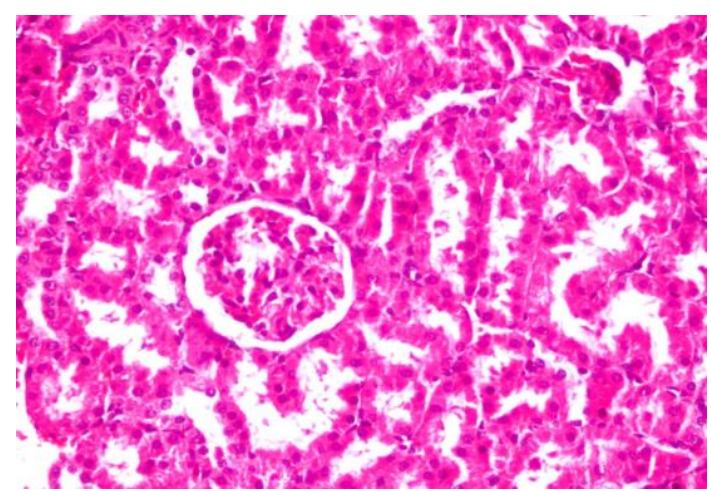

Figure 13: DMSO group: kidneys showing apparently normal glomeruli and renal tubules

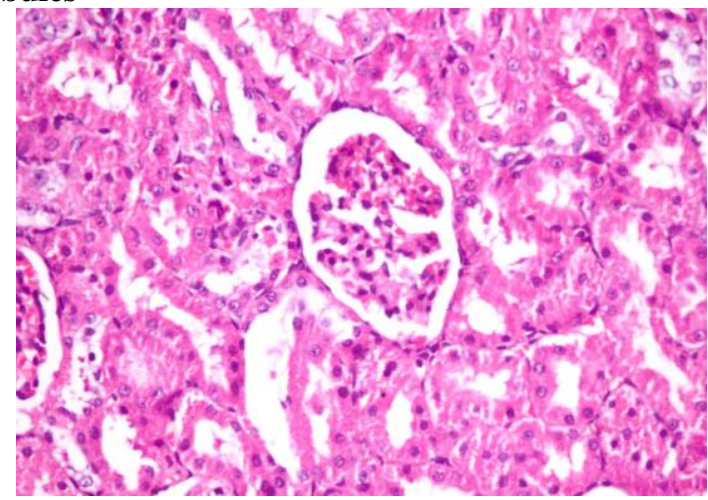

Figure 14: Ginger 200 + cisplatin: kidneys showing apparently normal glomeruli and renal tubules with moderate degenerative changes.

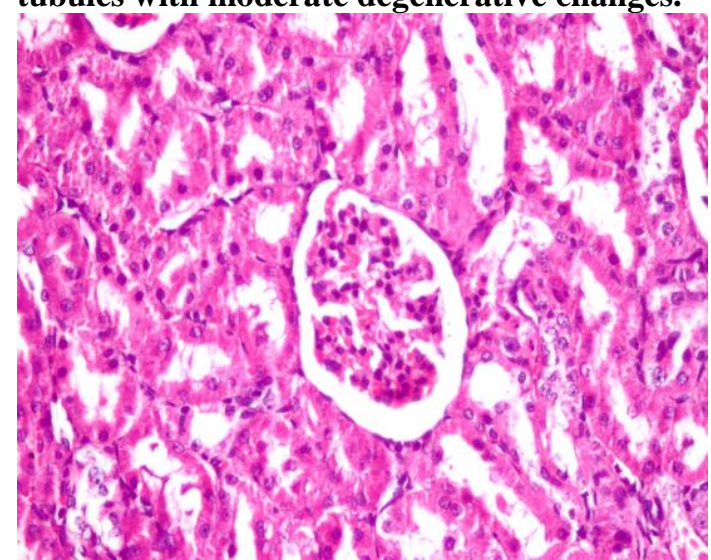

Figure 15: Ginger 400 + cisplatin: kidneys showing apparently normal glomeruli and renal tubules with minimal degenerative changes.

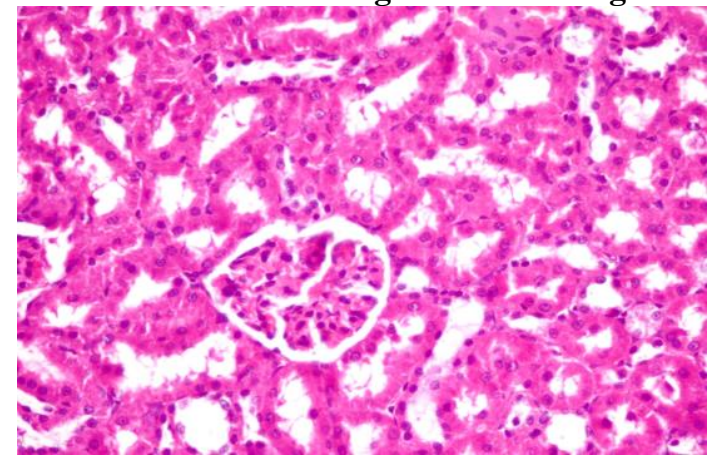

Figure 16: Ginger 600 + cisplatin: kidneys showing normal glomeruli and renal tubules with no pathological changes. 
Table 1: Kidney function tests in all studied groups.

\begin{tabular}{|c|c|c|c|}
\hline Group & \multicolumn{3}{|c|}{ Kidney functions } \\
\hline \multirow[b]{2}{*}{ Control } & & $\begin{array}{l}\text { Blood urea } \\
(\mathrm{mg} / \mathrm{dl})\end{array}$ & $\begin{array}{c}\text { Creatinine } \\
\text { (mg/dl) }\end{array}$ \\
\hline & $M e a n \pm S E$ & $27.5 \pm 0.6$ & $0.66 \pm 0.01$ \\
\hline \multirow{3}{*}{ DMSO } & Mean $\pm S E$ & $29.60 \pm 1.76$ & $0.70 \pm 0.06$ \\
\hline & $P *$ & 0.921 & 0.925 \\
\hline & $\% *$ & 7.6 & 6.1 \\
\hline \multirow{3}{*}{$\begin{array}{l}\text { Cisplatin } \\
\text { (Positive) }\end{array}$} & Mean $\pm S E$ & $159.5 \pm 16.56$ & $3.23 \pm 0.37$ \\
\hline & $P *$ & $<0.001$ & $<0.0001$ \\
\hline & $\% *$ & 480.0 & 390.5 \\
\hline \multirow{3}{*}{ Ginger only } & Mean $\pm S E$ & $25.3 \pm 1.9$ & $0.65 \pm 0.04$ \\
\hline & $P *$ & 0.919 & 0.981 \\
\hline & $\% *$ & -7.9 & -1.5 \\
\hline \multirow{5}{*}{$\begin{array}{c}\text { Ginger } \\
600+\text { cisplatin }\end{array}$} & Mean $\pm S E$ & $63.5 \pm 10.8$ & $1.6 \pm 0.2$ \\
\hline & $P *$ & 0.096 & 0.026 \\
\hline & $\% *$ & 130.9 & 147.5 \\
\hline & $P * *$ & 0.001 & $<0.001$ \\
\hline & $\% * *$ & -60.2 & -49.6 \\
\hline \multirow{5}{*}{$\begin{array}{c}\text { Ginger } \\
400+\text { cisplatin }\end{array}$} & Mean $\pm S E$ & $99.8 \pm 22.4$ & $1.8 \pm 0.2$ \\
\hline & $P *$ & 0.001 & 0.008 \\
\hline & $\% *$ & 263.0 & 177.8 \\
\hline & $P * *$ & 0.004 & 0.001 \\
\hline & $\% * *$ & -37.4 & -43.4 \\
\hline \multirow{5}{*}{$\begin{array}{c}\text { Ginger } \\
200+\text { cisplatin }\end{array}$} & Mean $\pm S E$ & $103.67 \pm 22.5$ & $2.12 \pm 0.5$ \\
\hline & $P *$ & 0.001 & 0.001 \\
\hline & $\% *$ & 277.0 & 220.7 \\
\hline & $P * *$ & 0.007 & 0.007 \\
\hline & $\% * *$ & -35.0 & -34.6 \\
\hline
\end{tabular}

$\mathrm{P} *=\mathrm{P}$ Value compared to control group; $\mathrm{P}^{* *}=\mathrm{P}$ Value compared to cisplatin (positive) group. The mean difference is significant at $\mathrm{P}<0.05 . \% *=$ Percent of change compared to control group; $\% * *=$ Percent of change compared to cisplatin (positive) group. 
Table 2: Mineral levels in all studied groups

\begin{tabular}{|c|c|c|c|c|c|}
\hline Group & \multicolumn{5}{|c|}{ Minerals } \\
\hline \multirow[b]{2}{*}{ Control } & & $\begin{array}{c}\mathrm{Ca} \\
(\mathrm{mg} / \mathrm{dl})\end{array}$ & $\begin{array}{c}\mathrm{K} \\
(\mathrm{mmol} / \mathrm{L})\end{array}$ & $\begin{array}{c}\mathrm{Mg} \\
(\mathrm{mg} / \mathrm{dl})\end{array}$ & $\begin{array}{c}\mathrm{Na} \\
(\mathrm{mEq} / \mathrm{L})\end{array}$ \\
\hline & Mean $\pm S E$ & $10.15 \pm 0.09$ & $6.275 \pm 0.1$ & $2.725 \pm 0.04$ & $144.0 \pm 0.7$ \\
\hline \multirow{3}{*}{ DMSO } & Mean $\pm S E$ & $10.12 \pm 0.03$ & $6.28 \pm 0.14$ & $2.72 \pm 0.05$ & $143.4 \pm 2.4$ \\
\hline & $P *$ & 0.884 & 0.985 & 0.963 & 0.754 \\
\hline & $\% *$ & -0.3 & 0.1 & -0.3 & -0.4 \\
\hline \multirow{3}{*}{$\begin{array}{l}\text { Cisplatin } \\
\text { (Positive) }\end{array}$} & $M e a n \pm S E$ & $9.59 \pm 0.08$ & $6.225 \pm 0.2$ & $2.69 \pm 0.09$ & $141.25 \pm 0.4$ \\
\hline & $P *$ & 0.005 & 0.841 & 0.853 & 0.130 \\
\hline & $\% *$ & -5.5 & -0.8 & -1.2 & -1.9 \\
\hline \multirow{3}{*}{ Ginger only } & Mean $\pm S E$ & $10.12 \pm 0.14$ & $6.266 \pm 0.16$ & $2.72 \pm 0.07$ & $144.3 \pm 0.8$ \\
\hline & $P *$ & 0.871 & 0.975 & 0.986 & 0.862 \\
\hline & $\% *$ & -0.3 & -0.1 & -0.1 & 0.2 \\
\hline \multirow{5}{*}{$\begin{array}{c}\text { Ginger } \\
600+\text { +cisplatin }\end{array}$} & $M e a n \pm S E$ & $10.08 \pm 0.1$ & $6.256 \pm 0.2$ & $2.716 \pm 0.2$ & $143.7 \pm 0.6$ \\
\hline & $P *$ & 0.745 & 0.945 & 0.966 & 0.862 \\
\hline & $\% *$ & -0.7 & -0.3 & -0.3 & -0.2 \\
\hline & $P * *$ & 0.013 & 0.899 & 0.889 & 0.182 \\
\hline & $\% * *$ & 5.2 & 0.5 & 0.9 & 1.7 \\
\hline \multirow{5}{*}{$\begin{array}{c}\text { Ginger } \\
400+\text { cisplatin }\end{array}$} & Mean $\pm S E$ & $9.97 \pm 0.2$ & $6.25 \pm 0.2$ & $2.71 \pm 0.18$ & $143.3 \pm 2.1$ \\
\hline & $P *$ & 0.373 & 0.925 & 0.946 & 0.728 \\
\hline & $\% *$ & -1.8 & -0.4 & -0.5 & -0.5 \\
\hline & $P * *$ & 0.054 & 0.920 & 0.911 & 0.249 \\
\hline & $\% * *$ & 4.0 & 0.4 & 0.8 & 1.5 \\
\hline \multirow{5}{*}{$\begin{array}{c}\text { Ginger } \\
200+\text { cisplatin }\end{array}$} & Mean $\pm S E$ & $9.95 \pm 0.23$ & $6.23 \pm 0.15$ & $2.69 \pm 0.21$ & $143.0 \pm 1.2$ \\
\hline & $P *$ & 0.332 & 0.876 & 0.864 & 0.602 \\
\hline & $\% *$ & -2.0 & -0.7 & -1.2 & -0.7 \\
\hline & $P * *$ & 0.065 & 0.973 & 0.998 & 0.331 \\
\hline & $\% * *$ & 3.8 & 0.1 & 0.0 & 1.2 \\
\hline
\end{tabular}

$\mathrm{P}^{*}=\mathrm{P}$ Value compared to control group; $\mathrm{P}^{* *}=\mathrm{P}$ Value compared to cisplatin (positive) group. The mean difference is significant at $\mathrm{P}<0.05$.

$\% *=$ Percent of change compared to control group; $\% * *=$ Percent of change compared to cisplatin (positive) group. 
Table 3: Antioxidant levels in all studied groups

\begin{tabular}{|c|c|c|c|c|}
\hline Group & \multicolumn{4}{|c|}{ Antioxidant } \\
\hline \multirow[b]{2}{*}{ Control } & & No $(\mu \mathrm{mol} / \mathrm{L})$ & $\begin{array}{c}\text { MDA } \\
(\mathrm{nmol} / \mathrm{g} \\
\text { tissue) }\end{array}$ & $\begin{array}{c}\text { Catalase } \\
(\mathbf{U} / g)\end{array}$ \\
\hline & $M e a n \pm S E$ & $18.39 \pm 2.2$ & $4.45 \pm 0.4$ & $42.9 \pm 1.5$ \\
\hline \multirow{3}{*}{ DMSO } & Mean $\pm S E$ & $18.44 \pm 0.7$ & $5.3 \pm 0.3$ & $36.2 \pm 0.9$ \\
\hline & $P *$ & 0.994 & 0.591 & 0.246 \\
\hline & $\% *$ & 0.3 & 19.1 & -15.6 \\
\hline \multirow{3}{*}{$\begin{array}{l}\text { Cisplatin } \\
\text { (Positive) }\end{array}$} & Mean $\pm S E$ & $55.81 \pm 3.86$ & $12.9 \pm 0.99$ & $27.4 \pm 1.2$ \\
\hline & $P *$ & $<0.001$ & $<0.001$ & 0.006 \\
\hline & $\% *$ & 203.4 & 190.5 & -36.1 \\
\hline \multirow{3}{*}{ Ginger only } & Mean $\pm S E$ & $16.4 \pm 1.4$ & $5.60 \pm 0.27$ & $36.7 \pm 0.48$ \\
\hline & $P *$ & 0.776 & 0.471 & 0.284 \\
\hline & $\% *$ & -10.6 & 25.7 & -14.4 \\
\hline \multirow{5}{*}{$\begin{array}{c}\text { Ginger } \\
600+c i s p l a t i n\end{array}$} & Mean $\pm S E$ & $22.9 \pm 8.6$ & $6.09 \pm 1.6$ & $35.6 \pm 9.1$ \\
\hline & $P *$ & 0.488 & 0.305 & 0.203 \\
\hline & $\% *$ & 24.8 & 36.7 & -17.2 \\
\hline & $P * *$ & $<0.001$ & 0.004 & 0.135 \\
\hline & $\% * *$ & -58.9 & -52.9 & 29.6 \\
\hline \multirow{5}{*}{$\begin{array}{c}\text { Ginger } \\
\text { 400+cisplatin }\end{array}$} & Mean $\pm S E$ & $25.1 \pm 3.2$ & $6.67 \pm 0.6$ & $31.5 \pm 1.7$ \\
\hline & $P *$ & 0.309 & 0.167 & 0.052 \\
\hline & $\% *$ & 36.7 & 49.7 & -26.6 \\
\hline & $P * *$ & $<0.001$ & 0.092 & 0.448 \\
\hline & $\% * *$ & -54.9 & -48.5 & 14.9 \\
\hline \multirow{5}{*}{$\begin{array}{c}\text { Ginger } \\
200+\text { cisplatin }\end{array}$} & Mean $\pm S E$ & $25.38 \pm 6.0$ & $7.40 \pm 1.97$ & $30.09 \pm 5.2$ \\
\hline & $P *$ & 0.290 & 0.069 & 0.030 \\
\hline & $\% *$ & 38.0 & 66.1 & -29.9 \\
\hline & $P * *$ & $<0.001$ & 0.378 & 0.621 \\
\hline & $\% * *$ & -54.5 & -42.8 & 9.7 \\
\hline
\end{tabular}

$\mathrm{P} *=\mathrm{P}$ Value compared to control group; $\mathrm{P}^{* *}=\mathrm{P}$ Value compared to cisplatin (positive) group. The mean difference is significant at $\mathrm{P}<0.05$.

$\% *=$ Percent of change compared to control group; $\% * *=$ Percent of change compared to cisplatin (positive) group. 
Table 4: Caspase-3 levels in all studied groups

\begin{tabular}{|c|c|c|}
\hline Group & \multicolumn{2}{|c|}{ Caspase-3 } \\
\hline \multirow[b]{2}{*}{ Control } & & Caspase-3 (ng/ml) \\
\hline & Mean $\pm S E$ & $2.55 \pm 0.09$ \\
\hline \multirow{3}{*}{ DMSO } & Mean $\pm S E$ & $2.575 \pm 0.12$ \\
\hline & $P *$ & 0.914 \\
\hline & $\% *$ & 0.8 \\
\hline \multirow{3}{*}{$\begin{array}{l}\text { Cisplatin } \\
\text { (Positive) }\end{array}$} & Mean $\pm S E$ & $4.35 \pm 0.08$ \\
\hline & $P *$ & $<0.001$ \\
\hline & $\% *$ & 70.3 \\
\hline \multirow{3}{*}{ Ginger only } & Mean $\pm S E$ & $2.77 \pm 0.16$ \\
\hline & $P *$ & 0.279 \\
\hline & $\% *$ & 8.5 \\
\hline \multirow{5}{*}{$\begin{array}{c}\text { Ginger } \\
600+\text { cisplatin }\end{array}$} & Mean $\pm S E$ & $2.755 \pm 0.16$ \\
\hline & $P *$ & 0.315 \\
\hline & $\% *$ & 7.9 \\
\hline & $P * *$ & $<0.001$ \\
\hline & $\% * *$ & -36.6 \\
\hline \multirow{5}{*}{$\begin{array}{c}\text { Ginger } \\
400+\text { cisplatin }\end{array}$} & Mean $\pm S E$ & $3.07 \pm 0.21$ \\
\hline & $P *$ & 0.031 \\
\hline & $\% *$ & 20.2 \\
\hline & $P * *$ & $<0.001$ \\
\hline & $\% * *$ & -29.4 \\
\hline \multirow{5}{*}{ Ginger 200+cisplatin } & Mean $\pm S E$ & $3.31 \pm 0.11$ \\
\hline & $P *$ & $<0.001$ \\
\hline & $\% *$ & 29.6 \\
\hline & $P * *$ & $<0.001$ \\
\hline & $\% * *$ & -23.9 \\
\hline
\end{tabular}

$\mathrm{P} *=\mathrm{P}$ Value compared to control group; $\mathrm{P}^{* *}=\mathrm{P}$ Value compared to cisplatin (positive) group. The mean difference is significant at $\mathrm{P}<0.05$.

$\% *=$ Percent of change compared to control group; $\% * *=$ Percent of change compared to cisplatin (positive) group. 